\title{
Stopping the SARS-CoV-2 surge in the USA-CDC recommendations and ground realities
}

\section{Introduction}

As of May 10, 2020, the United States of America (USA) has 1,367,079 cases of SARSCoV-2 and 80,773 deaths associated with the disease. New York alone has more than 333,000 cases and nearly 21,271 deaths. We are having about 20,000 new cases every day and the deaths are exceeding 1000 a day. There is overwhelming evidence that the most effective way of controlling the virus from spreading is restricting movement to prevent human to human exposure. As a result, economies were put on a lockdown worldwide. In the USA, lockdown began in California on March $19^{\text {th }}, 2020$, with stay home orders, allowing only for essential jobs, errands, and some exercise outside. Other states followed soon.

Opening the economy seems necessary. Lockdown was at least partially successful, but as expected, the economy slowed and jobs were lost. The latest job report per the US labor department showed 26 million Americans have been laid off and filed for unemployment benefits. The US unemployment now stands at $14.7 \%$ meaning 1 out of every 6 is jobless. This issue is the toll of the SARS-CoV-2 on the largest economy of the world. Most states now are looking toward the opening. Most of the "shelter in place" orders expire in May and some states like Georgia have already opened its businesses.

\section{Dangers involved with the reopening}

Re-opening will pose challenges. The biggest risk we face is a surge in the immediate cases of new infections. The second wave of infection in the fall has also been predicted. Prediction models have increased the United States deaths to 130,000 by early August this year given the reopening and relaxation of social distancing guidelines. The surge can overburden the healthcare system. If we were to see a second wave similar to the first, our present health care system will stretch again and mortality will increase directly due to SARS COV-2 and related conditions such as heart attacks and stroke. In order to reduce mortality and health care utilization, it is important to identify and secure the most vulnerable and protectable. The older and the frail are at particular risk of contracting the disease and losing their lives.

\section{Lessons learned until now about the most impacted group}

As per the Center for Disease Control and Prevention's (CDC) latest data set, among the dead from SARS-COV-2 in the USA, 80\% were 65 years or older and that has not changed since March $18^{\text {th }}, 2020$. As per CDC, on May $8^{\text {th }}, 2020$, the hospitalization rate was highest in people 65 years or older in age at 162.2 per 100,000 as compared to that rate in people 50-64 years of age was 79.0 per 100,000 . The cumulative hospitalization rate was 50.3 per 100,000 [1]. It is logical to conclude that the group facing maximum mortality will also need more intensive care support. The CDC also studied the number of people above 65 years of age requiring intensive care shown and found it to be $53 \%$ in that age group [2]. Patients older

Address for correspondence: Harpreet Singh, Sutter Gould Medical Foundation, Stockton, United States; e-mail: harpreet91@gmail.com DOI: 10.5603/ARM.a2020.0099

Received: 14.05.2020

Copyright (C) 2020 PTChP

ISSN 2451-4934 
than 65 years released from the hospital were also more likely to be readmitted or released to a nursing home or rehabilitation facility, as opposed to home.

\section{Living arrangements of people above 65 years of age}

Based on these facts, the demographics including living arrangements of people above 65 years of age were studied. The number of people living in the USA above 65 years of age is 49.2 million as per the last available census report for 2016. As per, 2018 profile of senior living by Administration for Community living and Administration of Aging in the USA, the majority of men and women over 65 years of age live in their own homes. About 1.2 million people lived in nursing homes in 2017 who were above 65 years of age and constituted $1 \%$ of their population. The percentage increases with age to $3 \%$ for people, between 75-84. However, about 9\% people lived in nursing homes that were above 85 years of age [3]. About 1.3 million people have been estimated to be living and working in nursing homes in the USA. Other long-term facilities include assisted living and intermediate care facilities that have about 800,000 and 75,000 patients respectively. About 3 million people work on these facilities as health care personnel (HCP) and support staff [4]. CDC has defined HCPs as health care providers like doctors, nurse practitioners, PAs, nurses, their aids, and trainees, emergency medical technicians, pharmacists, therapists, phlebotomists, technicians, and staff employed under the Environmental Services Department. There are 6 million people in this group as compared to the population of the USA, which is 328 million.

Despite lower percentages of people living in nursing homes, and the fact that they represented only $11 \%$ of total cases of SARS-CoV-2 cases, maximum death rate has been seen in residents of these facilities. A staggering 27,700 people died in long-term facilities in the USA as per database by New York Times [5]. These deaths accounted for one third of the deaths related to SARS-CoV-2, making it the most intensively hurt group of all. There are about 7,700 such facilities having 150,000 cases of the virus so far. It has been clear that patients in long-term facilities are particularly at risk for acquiring and dying from the corona virus. Advanced age, underlying health conditions make these patients vulnerable. Because of the enclosed environment and common utilities, it is easier for the virus to spread there. There is constant exposure as well from transitions to other health care services like dialysis units, wound care centers, physician appointments and hospitalizations. HCP's getting in and out of these facilities and move from one room to the other contributing to the exposure. Given the burden of the disease, the healthcare workforce has been stretched thin and some of these HCPs visit multiple facilities. This issue leads to HCP being both the host (could be asymptomatic) and the vector for SARS-CoV-2.

Benefits of controlling the virus in these facilities could be up to one-third reduction in mortality, reduced hospitalizations in the group, reduced re-hospitalization, saving resources, and beds in intensive care units for the younger population who will be more exposed now after the lockdown is relaxed. This strategy can be used to avoid overwhelming the health care system while providing for the patients below 65 years of age. The advantage is that restricting mobility is possible in these places as compared to the rest of the population. As the US is trying to open its economy, various organizations are helping to prevent the pandemic from worsening. The Center for Medicare and Medicaid services in the USA (CMS) is working towards helping long-term facilities reduce the impact of SARS-CoV-2. There is guidance available on topics like infection control and visitation policies and infection control in these facilities. CMS has issued directive on April $19^{\text {th }}, 2019$ that requires cases of SARS-CoV-2, to be reported directly to the organization, detected in Nursing Homes. Other major steps being taken include many states coming forward in allocating testing resources for these facilities. Experts agree that testing for SARS-CoV-2 is the key to moving forward and returning to business as usual. Measures like temperature check are not sufficient because of asymptomatic carriers. A study published in New England Journal of Medicine conducted in a Nursing Home in Seattle, USA, found that $50 \%$ of the residents tested positive for SARS-CoV-2 and did not have any symptoms [6]. Similarly, asymptomatic workers can easily walk in and start a new spread. There is a need to spot these carriers who are unaware of their own infection.

The ground reality is that unfortunately, even now, most of these facilities do not have enough tests to stop the outbreak. So far, the major organizations like CDC and CMS have not mandated testing of all the residents and staff. The leading experts like Mark Parkinson, CEO of the American Health Care Association, said that there are not enough tests available and only a small percen- 
tage of staff and residents are being checked [7]. Two-third of these facilities do not have access to enough tests as per Chris Laxton who is the director for the Society of post acute and long term care Medicine. (AMDA). [8] These facilities are not getting the same priority as hospitals.

\section{Suggestions}

We suggest special targeting of residents of long-term care facilities, and the HCPs involved in these facilities to stop the spread of SARS-CoV-2. Extreme measures including the highest testing numbers should be allocated to these facilities and rigorous infection control measures should be undertaken so that the SARS-CoV-2 virus do not enter and infect the patients in these facilities and if it does, the infection remains limited to facility. HCPs are usually younger than the residents of long-term facilities and are more likely to serve as a vector to SARS-COV-2. Increased testing can lead to an early exclusion from work to reduce the spread of SARS-CoV-2.Testing includes both RT-PCR (reverse transcriptase PCR) and the newer antibody testing. The long-term facilities should be prioritized as opposed to the younger population or urgent care facilities. About 150,000 tests are being done every day in the USA and there is need for increased allocation of resources toward towards the long-term care facilities at state and federal level.

Secondly, testing should follow prompt and specific infection control measures. Asymptomatic SARS-CoV-2 carriage leads to increased transmission. Separating positive patients to specific wards to stop the spread can follow early identification with increased testing.

Thirdly, a point prevalence survey is necessary for $\mathrm{NH}$ residents and HCP visiting the facility to successfully complete a test-based prevention strategy. National Guard teams are being deployed for the purpose but the need is to train the staff and provide necessary tests and personal protective equipment (PPE) so that all facilities can do their own testing. It is necessary that all residents of $\mathrm{NH}$ and other long-term facilities need to be tested frequently to curb the spread of SARS-CoV-2. Currently, available data suggests that where there are confirmed SARS COV-2 cases, there is an equal or greater number of asymptomatic SARS-CoV-2 carriers. Once PPS is carried out in these high incidence long-term facilities along with the HCP visiting them, necessary appropriate cohorting of these patients can be performed. A separate unit or facility can be created to keep these residents to curb the spread. Also, it is important to identify the asymptomatic SARS-CoV-2 carriers, and separating them would also be needed to complete the task. Meanwhile, if facility-wide PPS cannot be achieved, then at least separate units of symptomatic patients should undergo testing on a prioritized basis in these long-term facilities. There can be situations where resources may not allow facility-wide PPS and unit-wide PPS. At that point, prioritized testing of all symptomatic residents, residents admitted from high-risk hospitals, residents who leave the facilities frequently such as for the hemodialysis, wound care or rehabilitation reasons and residents coming in contact of symptomatic patients should be done.

With these strategies, the high-risk group of people should be secured so that the Corona viral surge can be stopped while we are re opening the economy.

\section{Conflict of interest}

None declared.

\section{References:}

1. A weekly update on Corona Virus by Center for Disease Control and Prevention. COVIDView, May $8^{\text {th }}$ update on SARS-CoV-2. Available at: www.cdc.gov/coronavirus/2019-ncov/ cases-updates/index.html. [Last accessed at: May $25^{\text {th }}, 2020$ ].

2. Severe Outcomes Among Patients with Coronavirus Disease 2019 (COVID-19) - United States, February 12-March 16, 2020. MMWR Morb Mortal Wkly Rep 2020; 69: 343-346. DOI: http://dx.doi.org/10.15585/mmwr.mm6912e2.

3. 2018 profile of senior living by Administration for community living and Administration of Aging, U.S. Census Bureau, the National Center for Health Statistics, and the Bureau of Labor Statistics. Available at: https://acl.gov/sites/default/files/ Aging\%20and\%20Disability\%20in\%20America/2018OlderAmericansProfile.pdf. [Last accessed at: May 25 ${ }^{\text {th }}, 2020$ ].

4. Chidambram P. State Reporting of Cases and Deaths Due to COVID-19 in Long-Term Care Facilities April 23, 2020. Available at: https://www.kff.org/medicaid/issue-brief/state-reporting-of-cases-and-deaths-due-to-covid-19-in-long-term-care-facilities/. [Last accessed at May $25^{\text {th }}, 2020$ ].

5. Yourish K, Lai R, Ivory D, et al. One-Third of All U.S. Coronavirus Deaths Are Nursing Home Residents or Workers. The New York Times, May $11^{\text {th }}, 2020$. Available at: www.nytimes. com/interactive/2020/05/09/us/coronavirus-cases-nursing-homes-us.html. [Last accessed at May 25 ${ }^{\text {th }}, 2020$ ].

6. Arons MM, Hatfield KM, Reddy SC, et al. Presymptomatic SARS-CoV-2 infections and transmission in a skilled nursing facility. N Engl J Med. DOI: 10.1056/NEJMoa2008457.

7. Stockman F, Richtel M, Ivory D, et al. coronavirus claims at least 6900 nursing home deaths in US. The New York Times, April $17^{\text {th }}, 2020$. Available at: https://www.nytimes. com/2020/04/17/us/coronavirus-nursing-homes.html. [Last accessed at: May $\left.25^{\text {th }}, 2020\right]$.

8. Associated press.11,000 Deaths: Ravaged Nursing Homes Plead for More Testing April 24, 2020. Available at: https://couriernewsroom.com/2020/04/23/10000-deaths-nursing-homes-more-testing. [Last accessed at: May $\left.25^{\text {th }}, 2020\right]$. 